\title{
Factors Influencing Pre-Hospital Delay In Patients with Acute Myocardial Infarction
}

\author{
MD. FAKHRUL ISLAM KHALED, SAJAL KRISHNA BANERJEE, DIPAL KRISHNAADHIKARY, MSI TIPU \\ CHOWDHURY, MANZOOR MAHMOOD, MD. MUKHLESUR RAHMAN, KHURSHED AHMED, \\ MOHAMMAD FAISAL IBN KABIR, SANJIDAANSARI \\ Department of Cardiology, Bangabandhu Sheikh Mujib Medical University, Dhaka. \\ Address of Correspondence: Dr. Md. Fakhrul Islam Khaled, Assistant Professor, Department of Cardiology, Bangabandhu Sheikh \\ Mujib Medical University, Dhaka. Email: drfikhaled@gmail.com
}

\begin{abstract}
:
Acute coronary syndrome is a lethal condition. Treatment modality and success mostly depend on time yielded since onset of symptoms. It is known for more than 30 years that delay between symptom onset and treatment of less than 60 min are desirable, but pre hospital delays remain unacceptably long worldwide including Bangladesh. A greater understanding of the contributing factors may help to reduce delays. A number of sociodemographic, clinical, social and proximal factors have been associated with pre hospital delay. The total pre hospital delay period consists of two component: time taken by patients to recognize that their symptoms are serious and to contact medical help (decision time) and the time taken from requesting help to admission where emergency coronary care is available (time to hospital delay). Different factors may affect these two components. In hospital delay also known as door-to-treatment, is defined as time from arriving to hospital to initiation of reperfusion therapy. Regardless of how to shorten in hospital delay, if the pre hospital delay is not reduced, then reperfusion therapy cannot achieve the best results. We set out to discover what factors are specifically associated with three components: decision time, home to hospital delay and First Medical Contact (FMC) to revascularization delay. This review may help the National health management system to identify the factors associated with treatment delay in ACS and thus reduces ACS related morbidity and mortality.
\end{abstract}

Key words: Acute Myocardial Infarction; Pre hospital delay; Factors

University Heart Journal 2019; 15(2): 79-85

\section{Introduction:}

Acute myocardial infarction is a dangerous disease with a high mortality rate. For AMI patients, the fate of the heart and the patient's life depends on time to beginning of effective treatment in addition to other factors such as severity of disease and involved vessels etc. ${ }^{1}$ The key factor is whether reperfusion therapy is started timely after the onset of symptoms, and the benefit of reperfusion therapy depends on the time. ${ }^{2}$ Guidelines emphasize the need to minimize reperfusion delay time for patients with acute myocardial infarction. ${ }^{3}$ Delay before the initiation of reperfusion therapy for AMI can be divided into two distinct time periods: pre-hospital delay and in-hospital delay. Prehospital delay is the time from onset of symptoms to arrival to the hospital. In-hospital delay, also known as door-to treatment, is defined as the time from arriving to the hospital to the initiation of reperfusion therapy.1 Pre-hospital delay can be divided into two time periods: patient delay (PD) time and transportation delay (TD) time. Patient delay is time from the onset of symptoms to making the initial decision to seek for professional healthcare facility, and transportation delay is the time from making the initial decision to seek professional healthcare facility to arrival at the hospital. ${ }^{4}$ Pre-hospital delay is mainly caused by the patient's own decisions and is much longer than in-hospital delay and the time needed to decide on initiating reperfusion therapy. ${ }^{5}$ Regardless of how to shorten in-hospital delay, if the pre-hospital delay is not reduced, then reperfusion therapy cannot achieve the best results. ${ }^{6}$ However, patient delay time, which accounts for $75 \%$ of the total pre-hospital delay time, ${ }^{7}$ hasnot changed in the past 10 years. ${ }^{89}$ Thus, reducing patient delay time is very important for AMI patients..$^{10}$ The median interval between reported onset of symptoms and hospital admission is 5 hours.

\section{Objectives:}

This review study evaluated the cause of pre hospital delay either as decision time delay, home to hospital delay and first medical contact (FMC) to revascularization delay and also evaluated the factors associated with this delay. 


\section{Rationality of the review}

Data related to ischemic heart disease (IHD) and pre hospital delay in Bangladesh are insufficient, suffer from statistical flaws and are not readily available. Few articles were published in national, non-indexed journals, which are not available online and difficult to procure. Recognizing these limitations, the present review has been planned to compile the available data on this important public health issue. This review will hopefully encourage future research and act as an important source of information.

\section{Methods:}

Cross sectional analytical study.

\section{Factors Infleuncing Pre Hospital Delay}

\section{Age}

Increased age has been associated with a longer prehospital delay in many studies. ${ }^{11-15}$ This may be explained by the following several reasons: (1) The elderly have reduced physiological function and a lower ability to perceive pain. (2) Older patients are more likely to have atypical symptoms compared with younger patients and have more comorbidities, which may result in a delay for seeking medical care ${ }^{16,17}$ and limit their correct recognition of warning symptoms. ${ }^{18,19}$ (3) The elderly have insuffcient perceptions of AMI and do notwant to trouble the family with their symptoms, and thus, the actual rescue time will be longer. ${ }^{20}$ However other researchers could not find a statistically significant result for the effect of age on delay. $6,21,22$

\section{Gender}

Female gender was a significant variable in predicting delay. Female patients with AMI had a prolonged decisionmaking process compared with males. ${ }^{23}$ There are several potential explanations for this finding: (1) The incidence of AMI for males corresponds to that of older females. ${ }^{24}$ Older female patients often have other chronic diseases, which is a disadvantage for them in terms of their medical care and treatment. ${ }^{25}(2)$ Females are more likely to have atypical symptoms compared with males, making females less apt to interpret their symptoms, such as being related to a heart attack. ${ }^{26,27}(3)$ Females appear to have a belief that AMI is a "male" disease and that they are associated with a lower risk of AMI.In contrast, other studies have not found significant gender differences. ${ }^{24,29}$

Age and gender can affect each other. The elderly have a largegender difference for pre-hospital delay, and older females delaysignificantly longer than males; however, the reason may be because the incidence of heart disease of women corresponds tothat of men who are 10 years younger. ${ }^{17,30}$

\section{Marital status}

Single, widowed or divorced patients have a longer delay time for seeking care compared to patients who are married. ${ }^{31}$ The reason may be that there is no one to consult immediately. Among males, married or common law status was strongly associated with earlier health-seeking behaviour in the setting of acute myocardialinfarction. Among females, married or common law status was not associated with a similar reduction in delay before seeking medical attention. ${ }^{32}$ However, a study reported that marital status is not associated with pre hospital delay. ${ }^{29}$

\section{Previous history}

Patients with a history of diabetes, hypertensionor angina pectorishave been found to delay longer than those without these conditions. However, several studieshave reported that patients with prior AMI delay less, but many others did not find any association between delay and history of AMI. ${ }^{33}$

\section{Health insurance}

Patients with health insurance have a shorter delay than those without insurance. ${ }^{34}$

\section{Economic level}

Several studies have reported that the economic level is associated with pre-hospital delay,e.g., patients with a higher income have an earlier presentation for care. ${ }^{35}$

\section{Education level}

Low-education levels were a significant determinant of longer pre-hospital delay. ${ }^{36}$

\section{Living condition}

Living alone was an independent predictor of longer delay time. $^{5}$

\section{Race}

Minorities who were more likely to have specific cultural health beliefs and perceptions related to medical behaviour were associated with a significantly longer delay. ${ }^{37}$

\section{Symptoms}

\subsection{Types}

The classic symptoms of an AMI include chest pain, but some investigators found that $20 \%-33.3 \%$ of patients with AMI did not experience central chest pain at all.6,38Some atypical symptoms, such as weakness, shortness of 
breath,anxiety,abdominal discomfort or sweating can occur when experiencing an AMI39and were associated with a substantially longer pre-hospital delay. ${ }^{24,36}$

\subsection{Intensity}

Increased symptom intensity and having fast onse symptoms(symptomsthatdevelop rapidly) were associated with a shorter pre-hospital delay. $6,21,22,40$

\subsection{Duration}

Having continuous symptoms predicted a short prehospital Delay6and having intermittent symptoms predicted a longer delay. ${ }^{29}$

\section{Contextual factors}

4.1. Time when the symptoms occur having symptom onset at night was associated with a longerpre-hospital delay. ${ }^{41}$ There may be no other person available to helpat night, and thus, the patients did not want to trouble others andplanned to seek healthcare during the daytime. Another reason may be that it is difficult to find a way of transportation and a person to help at night. ${ }^{33}$

\subsection{Location where symptoms occur}

Being home ${ }^{21}$ or in a public place ${ }^{21}$ when symptoms began resulted in a longer delay to treatment. However, one study found no significant differences between early and late responders with regard to location of where the symptoms began. ${ }^{42}$

4.3. Whether there is a bystander when the symptoms occur

Patients who experienced symptoms alone had longer delays compared to patients who had company. ${ }^{22}$ Having someone present when the symptoms occur can not only reduce fear but also lead to a responsible decision regarding treatment and thus ashorter pre hospital delay. ${ }^{43}$

\section{Cognitive and affective factors}

\subsection{Cognitive factors}

\subsubsection{Symptom identification}

The patient's correct identification of symptoms was an important predictor for delay time. ${ }^{44}$ Patients who experienced symptoms that are different from those expected to be associated with AMI delayed care, and patients who correctly recognised the symptoms of AMI experienced less delay. ${ }^{29}$

\subsubsection{Symptom attribution}

Patients who thought that their symptoms were heart relatedsought treatment faster than individuals who did not relate theirsymptoms to a heart problem. ${ }^{21,22,45}$
5.1.3. The perception of severity and susceptibility

Lack of perceived seriousness of symptoms $6,{ }^{46}$ and lack of perceived susceptibility to heart disease ${ }^{47}$ were associated with a longer delay.

\subsubsection{Perceived control symptoms}

Patients who perceived being able to cope with or control symptoms were associated with an increased delay. ${ }^{21,46}$

\subsubsection{Knowledge related to AMI}

Being able to recognize the importance of a short delay whenexperiencing an AMI was associated with a significant delay whendeciding to seek treatment. ${ }^{22}$

\subsection{Affective factors}

\subsubsection{Fear}

Fear of the consequences can significantly shorten the patients'decision time. ${ }^{22}$

\subsubsection{Denial of AMI}

Denial is a self-defence mechanism toward illness because people tend to reject ideas that are associated with potentially unpleasant experiences or feelings. ${ }^{48}$ Thus, denial is a common reaction among patients with signs of $\mathrm{AMI}^{43,49}$ and can causeconsiderable pre-hospital delay. ${ }^{50}$

\subsubsection{Fear of troubling others.}

Longer pre-hospital delay was perpetuated by the fear of troubling other family members. ${ }^{51}$

\section{Behavioural factors}

\section{1. (Calling) consulting others}

There are two scenarios. First, calling or visiting the primary care provider (PCP), usually in foreign countries, was associated with a substantially long pre-hospital delay. ${ }^{6}$ The potential reason is that the consultation process itself is very time-consuming. However, telling members, friends or colleagues may play a crucial role in helping the victims to overcome their fear of the disease or denial about their symptoms, which occurs more commonly in China, and the patients experienced a shorter delay. ${ }^{6,10,52}$

\subsection{Self-treatment}

Self-treatment with drugs or rest can lead to a long prehospital delay. ${ }^{53}$

\subsection{Transportation}

This factor is mainly divided into calling for ambulance transport and self-transport. Patients choosing ambulance transportation reduced their pre-hospital delay 
time. ${ }^{6,21}$ However, patients choosing self-transport delayed treatment due to the lack of timely treatment. ${ }^{33}$ The most frequent reason for not choosing an ambulance was that the patient did not perceive the symptoms to be sufficiently serious to merit a dramatic action, such as calling the EMS. ${ }^{54}$ The second most common reason for not choosing ambulance transport was that the patients believed that self- transport would be faster. ${ }^{55}$ The last reason was that the ptient became aware of the fact that the ambulances are only a mode of transport and did not understand the capability of paramedics.

\section{Clinical parameters and risk factors}

7.1. Severity - Patients in cardiogenic shock after cardiac arrest arrive at the hospital sooner than others. ${ }^{56,57}$,For these patients, the acute medical situation is so dramatic as to leave no room for subjective ambivalence. On the other hand, severity parameters such as the size of the infarct, ${ }^{57}$ enzyme values, ejection fraction, the number of occluded arteries, and the vital signs do not seem to affect the PHT significantly. ${ }^{58}$

7.2. Hypertension is associated with a longer $\mathrm{PHT}^{56}$, with a median of 2.2 hours as compared to 2.0hours in normotensive patients. Three studies with smaller case numbers revealed no significant difference. One reason for this may be a less sensitive perception of pain in patients with hypertension as a risk factor for myocardial infarction. 59

7.3. Diabetes-With a few exceptions most studies have indicated that diabetes significantly predicts a longer PHT. ${ }^{56}$ This may be due to the suppression of pain by diabetic neuropathy. 60

7.4. Smoking - In three larger studies involving more than 2000 patients each, ${ }^{56}$ smokers had significantly shorter prehospital times than non-smokers. The reason for this is perhaps that the risk of myocardial infarction among smokers has been well publicized by the media. ${ }^{61}$

The potential influence of body-mass index, hypercholesterolemia and physical activity on prehospital times has only been investigated in the GREECS study; ${ }^{62}$ no significant effect was found for any of these factors.

\section{Pre-existing heart disease}

8.1. Angina pectoris - Patients with a prior history of angina pectoris tend to have a longer prehospital time. ${ }^{56}$ Apparently, these patients have more difficulty identifying and attaching the proper significance to the chest pain of myocardial infarction. The ARIC study, ${ }^{63}$ however, found no effect of angina pectoris on the PHT, and the NRMI- $2^{64}$ study and that of Kentsch et $\mathrm{al}^{65}$ even found that patients with prior angina pectoris arrived at the hospital earlier than others.

8.2. Previous myocardial infarction - Though one might imagine that patients who have previously sustained a myocardial infarction would arrive at the hospital morequickly in the event of reinfarction, this is by no means necessarily the case. The MITRAplus study ${ }^{61}$ and a Swedish study with more than 2000 patients ${ }^{66}$ showedno difference in PHT between patients with a first infarction and patients with a reinfarction. In the first study period of the Worcester Heart Attack Study (1986-1990), patients with reinfarctions actually took longer to get to a hospital (odds ratio 1.6 for a more than six-hour delay, as compared to patients with a first infarction) ${ }^{67}$. A Danish study came to the conclusion that patients with a reinfarction have a markedly shorter PHT, while patients with a previous mechanical revascularization procedure interpreted their symptoms correctly but nevertheless had significantly longer decision times. ${ }^{68}$

8.3. Previous revascularization or bypass operation - In most studies, these patients were found to arrive at the hospital sooner than others ${ }^{56,57}$ perhaps because of the sensitization of their families and treating physicians by the previous events.

\section{Discussion:}

On both the national and the international level, the prehospital time (PHT) is the most important factor leading to a temporal delay in the initiation of treatment foracute myocardial infarction. The studies that have been performed to date show that the most important factors influencing the PHT are the sex and age of the patient and the patient's misinterpretation of the symptoms. Empirical data on the effect of psychological mechanisms and coping strategies remain scarce at present.

One cannot yet draw a clear risk profile for "latecomers" that would be of use in everyday clinical practice and in patient education. There is still no theoreticallywellfounded and empirically confirmed basis for understanding patients' decisional behavior thus predicting their actions. There is a consensus, however,that general knowledge about the typical symptoms of heart attack is a necessary foundation of prevention but still does not suffice to prepare patients adequately for an acute crisis. ${ }^{69}$

In the future, the psychosocial and economic conditionsof the population will have to be considered more closely, patients at high risk will have to receive greater individual 
attention, and more sex-specific patient education will have to be provided . Preventive action will have to be tailored more specifically to the groups that are most at risk. It would be desirable to develop predictive algorithms for decisional behavior in groups with well-defined

identifying features (e.g., age $<60$; female sex; anxious avoidant behavior style), so that individualized prevention strategies could be offered.A further opportunity to identify patients at risk seems to be provided ${ }^{70}$ by observation of the prodromalphase of acute myocardial infarction. In the days preceding the acute event, many patients suffer increased irritability, depressive mood, unexplained fatigue, oranxiety. ${ }^{71,72}$ Physicians consulted because of such symptoms should think of the possibility of an impending myocardial infarction and take the corresponding steps to inform the patient about what to do in case this happens.

\section{Conclusion:}

Factors influencing pre-hospital patient delay for patients with acute myocardial infarction vary, and many research results are also contradictory regarding factors such as age, gender, and previous myocardial infarction. In addition, there are some interplay factors, such as between age and gender, gender and marital status, and cognitive and affective factors on the behavioural reaction. Nevertheless, predicting factors that could lead to delay using investigations of different populations could provide a reference to help professional medical care providers to developsome strategies to reduce the delay time.Well-designed future studies are needed to better understand the influencing factors related to patient delay and to resolve the controversy surrounding these associations. In addition, targeted intervention measures have been undertaken according to these factors with the goal of reducing the extent of pre-hospital delay in patients with signs and symptoms of AMI.

\section{Conflicts of interest}

All the contributing authors declare no conflicts of interest.

\section{References:}

1. Xie L, Huang SF, Hu YZ. Factors influencing pre-hospital patient delay in patients with acute myocardial infarction. Chinese Nursing Research 2015; 2: 75-9

2. Wang LJ, Liu Y, Liu XF, et al. Investigating the factors of affecting the treatment delay of AMI patients. Nurs Pract Res. 2012;9:8e10 [in Chinese].

3. Guidelines on Myocardial Revascularization. The task force on myocardial revascularization of the European society of
Cardiology (ESC) and the European association for Cardiothoracic surgery (EACTS). Eur Heart J. 2010;31:2501.

4. Cui G, Xu WL, Li BH. Researching pre-hospital delay time distribution and influence factor of ST segment elevation acute myocardial infarction patients.Contemp Med. 2013;19:30e31 [in Chinese].

5. Perkins-Porras L, Whitehead DI, Strike PC, et al. Pre-hospital delay in patients with acute coronary syndrome: factors associated with pre-hospital delay patient decision time and home-to- hospital delay. Eur J Cardiovasc Nurs. 2009;8:26e33.

6. Johansson I, Str•omberg A, Swahn E. Factors related to delay times in patients with suspected acute myocardial infarction. Heart Lung. 2004;33:291e300.

7. Hirvonen TP, Halinen MO, Kala RA, Olkinuora JT. Delays in thrombolytic therapy for acute myocardial infarction in Finland. Results of a national thrombolytic therapy delay study. Finnish Hospitals' Thrombolysis Survey Group. Eur Heart J. 1998;19:885e892.

8. Goldberg RJ, Spencer FA, Fox KAA, et al. Prehospital delay in patients with acute coronary syndromes (from the global registry of acute Coronary Events [GRACE]). Am J Cardiol. 2009; 103:598e603.

9. Spencer FA, Montalescot G, Fox KAA, et al. Delay to reperfusion in patients with acute myocardial infarction presenting to acute care hospitals: an international perspective. Eur Heart J. 2010;31:1328e1336.

10. Henriksson C, Larsson M, Arnetz J, et al. Knowledge and attitudes toward seeking medical care for AMI-symptoms. Int J Cardiol. 2011;147:224e227.

11. Ganova-Iolovska M, Kalinov K, Geraedts M. Quality of care of patients with acute myocardial infarction in Bulgaria: a cross-sectional study. BMC Health Serv Res. 2009;9:15.

12. Sail I, Acar Z, Ozer O, et al. Factors associated with prolonged prehospital delay in patients with acute myocardial infarction. Turk Kardiyol Dem Ars. 2008;36: 156e162.

13. Saezynski JS, Yarzebski J, Lessard D, et al. Trends in prehospital delay in patients with acute myocardial infarction (from the Worcester Heart Attack Study). Am J Cardiol 2008;102: $1409 \mathrm{e} 1594$

14. Ting HH, Bradley EH, Wang Y, et al. Factors associated with longer time from symptom onset to hospital presentation for patients with ST-elevation myocardial infarction. Arch Intern Med. 2008;168:959e968.

15. Nguyen HL, Saczynski JS, Gore JM, Goldberg RJ. Age and sex differences in duration of prehospital delay in patients with acute myocardial infarction: a systematic review. Circ Cardiovasc Qual Outcomes. 2010;3:82e92.

16. Goldberg RJ, Steg PG, Sadiq I, et al. Extent of, and factors associated with, delay to hospital presentation in patients with acute coronary disease (the GRACE registry). Am J Cardiol. 2002;89:791e796.

17. Isaksson RM, Holmgren L, Lundblad D, Brulin C, Eliasson M. Time trends in symptoms and prehospital delay time in women vs. men with myocardial infarction over a 15 -year period. 
The Northern Sweden MONICA Study. Eur J Cardiovasc Nurs. 2008;7(2), 152e140.

18. Ladwig $\mathrm{KH}$, Meisinger $\mathrm{C}$, Hymer $\mathrm{H}$, et al. Sex and age specific time patterns and long term time trends of pre-hospital delay of patients presenting with acute ST-segment elevation myocardial infarction. Int J Cardiol. 2011;152:350e355.

19. Fokkema ML, Wieringa WG, Horst IC, Boersma E, Zijlstra F, de Smet BJ. Quantitative analysis of the impact of total ischemic time on myocardial perfusion and clinical outcome in patients with ST-elevation myocardial infarction. Am J Cardiol. 2011;108:1536e1541.

20. Liang H, Liu Y, Zhao YM, et al. Efficacy of different treatments for Elderly AMI patients. Chin J Heart Dis. 2010;12:319e322 [in Chinese].

21. Lesneski L. Factors influencing treatment delay for patients with acute myocardial infarction. Appl Nurs Res. 2010;23:185e190.

22. Herlitz J, Thuresson M, Svensson L, et al. Factors of importance for patients' decision time in acute coronary syndrome. Int J Cardiol. 2010;141:236e242.

23. Heer T, Schiele R, Schneider S, et al. Gender differences in acute myocardial infarction in the era of reperfusion (the MITRA registry). Am J Cardiol. 2002;89: 511e517.

24. Lovlien M, Schei B, Hole T. Prehospital delay, contributing aspects and responses to symptoms among Norwegian women and men with first time acute myocardial infarction. Eur J Cardiovasc Nurs. 2007;6:308e313.

25. Rosenfeld AG. State of the heart: building science to improve women's cardiovascular health. Am J Crit Care. 2006; $15: 556 \mathrm{e} 567$.

26. Patel H, Rosengren A, Ekman I. Symptoms in acute coronary syndromes: does sex make a difference? Am Heart J. 2004;148:27e33.

27. Canto JG, Goldberg RJ, Hand MM, et al. Symptom presentation of women with acute coronary syndromes: myth vs reality. Arch Intern Med. 2007;167: 2405e2413.

28. Herning M, Hansen PR, Bygbjerg B, Lindhardt T. Women's experiences and behaviour at onset of symptoms of ST segment elevation acute myocardial infarction. Eur $\mathrm{J}$ Cardiovasc Nurs. 2011;10:241e247.

29. Noureddine S, Adra M, Arevian M, et al. Delay in seeking health care for acute coronary syndromes in a Lebanese sample. J Transcult Nurs. 2006;17: 341e348.

30. Maynard C, Weaver WD, Lambrew C, Bowlby LJ, Rogers WJ, Rubison RM. Factors influencing the time to administration of thrombolytic therapy with recombinant tissue plasminogen activator (data from the National registry of myocardial Infarction). Participants in the National registry of myocardial Infarction. Am J Cardiol. 1995;76:548e552.

31. Fournier S, Muller O, Ludman AJ, Lauriers N, Eeckhout E. Influence of socioeconomic factors on delays, management and outcome amongst patients with acute myocardial infarction undergoing primary percutaneous coronary intervention. Swiss Med Wkly. 2013;143:w13817.
32. Atzema CL, Austin PC, Huynh T, et al. Effect of marriage on duration of chest pain associated with acute myocardial infarction before seeking care. CMAJ. 2011;183:1482e1491.

33. Xie ZH, Zeng SY, Huang WF. Analysis the factors about before treatment delay time of acute myocardial infarction patients. Chin Pharm Guide. 2012;10: 460e461 [in Chinese].

34. Smolderen KG, Spertus JA, Nallamothu BK, et al. Health care insurance, financial concerns, and delays to hospital presentation in acute myocardial infarction. JAMA. 2010;303:1392e1400.

35. Foraker RE, Rose KM, McGinn AP, et al. Neighbourhood income. Health insurance, and prehospital delay for myocardial infarction: the atherosclerosis risk in communities study. Arch Intern Med. 2008;168:1874e1879.

36. Khan MS, Jafary FH, Faruqui AM, et al. High prevalence of lack of knowledge of symptoms of acute myocardial infarction in Pakistan and its contribution to delayed presentation to the hospital. BMC Public Health. 2007;7:284.

37. Klingler D, Green-Weir R, Nerenz D, et al. Perceptions of chest pain differ by race. Am Heart J. 2002;144:51e59.

38. Thygesen K, Alpert JS, Jaffe AS, et al. Third universal definition of myocardial infarction. Circulation. 2012;126:2020e2035.

39. Lefler L. The advanced practice nurse's role regarding women's delay in seeking treatment with myocardial infarction. J Am Acad Nurse Pract. 2002;14: 449e456.

40. Noureddine S, Arevian M, Adra M, Puzantian H. Response to signs and symptomsof acute coronary syndrome: differences between Lebanese men and women. Am J Crit Care. 2008; 17:26e35.

41. Guo JC, Hua Q, Liu DX. Factors related to patient delay time in patients with acute myocardial infarction ST segment elevation and essential hypertension. Am J Hypertens. 2005;18:219e220 [in Chinese].

42. Wu Y, Zhang Y, Li YQ, Hong BL, Huang CX. Factors associated with the extent of care-seeking delay for patients with acute myocardial infarction in Beijing. Chin Med J (Engl). 2004;117:1772e1777.

43. Pattenden J, Watt I, Robert J, et al. Decision making process in people with symptoms of acute myocardial infarction: qualitative study. BMJ. 2002;324: 1006e1010.

44. Ryan CJ, Zerwic JJ. Perceptions of symptoms of myocardial infarction related to health care seeking behaviors in the elderly. J Cardiovasc Nurs. 2003;18:184e196.

45. Fox-Wasylyshyn SM, El-Masri M, Artinian NT. Testing a model of delayed careseeking for acute myocardial infarction. Clin Nurs Res. 2010;19:38e54.

46. Morgan DM. Effect of incongruence of acute myocardial infarction symptoms on the decision to seek treatment in a rural population. J Cardiovasc Nurs. 2005;20:365e371.

47. Rosenfeld AG. Treatment-seeking delay among women with acute myocardial infarction: decision trajectories and their predictors. Nurs Res. 2004;53:225e236.

48. Stenstrom U, Nilsson AK, Stridh C, et al. Denial in patients with a first-time myocardial infarction: relations to pre-hospital 
delay and attendance to a cardiac rehabilitation programme. Eur J Cardiovasc Prev Rehabil. 2005;12: 568e571.

49. Rosenfeld AG, Gilkeson J. Meaning of illness for women with coronary heartdisease. Heart Lung. 2000;29:105e112.

50. Buckley T, McKinley S, Gallagher R, et al. The effect of education and counselling on knowledge, attitudes and beliefs about responses to acute myocardial infarction symptoms. Eur J Cardiovasc Nurs. 2006;6:105e111.

51. O'Gara PT, Kushner FG, Ascheim DD, et al. 2013 ACCF/ AHA guideline for the management of ST-elevation myocardial infarction: a report of the American College of Cardiology Foundation/American heart association task force on practice guidelines. Circulation. 2013;127:e369ee373.

52. Thuresson M, Jarlov MB, Lindahl B, et al. Thoughts, actions, and factors associated with prehospital delay in patients with acute coronary syndrome. Heart Lung. 2007;36:398e409.

53. Leslie WS, Urie A, Hooper J, et al. Delay in calling for help during myocardial infarction: reasons for the delay and subsequent pattern of accessing care. Heart. 2000;84:137e141.

54. Lozzi L, Carstensen S, Rasmussen H, et al. Why do acute myocardial infarction patients not call an ambulance? an interview with patients presenting to hospital with acute myocardial infarction symptorns. Intern Med J. 2005;35: $668 \mathrm{e} 671$.

55. Thuresson M, Jarlov MB, Lindahl B, et al. Factors that influence the use of ambulance in acute eoronarysyndrome. Am Heart J. 2008;156:170e176.

56. Goldberg RJ, Steg PG, Sadiq I et al.: Extent of, and factors associated with delay to hospital presentation in patients with acute coronary disease (the GRACE registry). Am J Cardiol 2002; 89: 791-6.

57. Leizorovicz A, Haugh MC, Mercier C, Boissel JP: Prehospital and hospital time delays in thrombolytic treatment in patients with suspected acute myocardial infarction. Analysis of data from the EMIP study. European Myocardial Infarction Project. Eur Heart J 1997; 18: 248-53.

58. Moser DK, McKinley S, Dracup K, Chung ML: Gender differences in reasons patients delay in seeking treatment for acute myocardial infarction symptoms. Patient Educ Couns 2005; 56: 45-54.

59. Falcone C, Auguadro C, Sconocchia R, Angoli L: Susceptibility to pain in hypertensive and normotensive patients with coronary artery disease: response to dental pulp stimulation. Hypertension 1997; 30: 1279-83.
60. Jermendy G: Clinical consequences of cardiovascular autonomic neuropathy in diabetic patients. Acta Diabetol 2003; 40 Suppl 2: 370-4.

61. Mark B, Meinertz T, Fleck E et al.: Stetige Zunahme der Prähospitalzeit beim akuten Herzinfarkt. Dtsch Arztebl 2006; 20: $1378-83$.

62. Pitsavos C, Kourlaba G, Panagiotakos DB, Stefanadis C: Factors associated with delay in seeking health care for hospitalized patients with acute coronary syndromes: the GREECS study. Hellenic J Cardiol 2006; 47: 329-36.

63. McGinn AP, Rosamond WD, Goff DC Jr., Taylor HA, Miles JS, Chambless L: Trends in prehospital delay time and use of emergency medical services for acute myocardial infarction: experience in 4 US communities from 1987-2000. Am Heart J 2005; 150: 392-400.

64. Goldberg RJ, Gurwitz JH, Gore JM: Duration of, and temporal trends (1994-1997) in prehospital delay in patients with acute myocardial infarction: the second National Registry of Myocardial Infarction. Arch Intern Med 1999; 159: 2141-7.

65. Kentsch M, Rodemerk U, Muller-Esch G et al.: Emotional attitudes toward symptoms and inadequate coping strategies are major determinants of patient delay in acute myocardial infarction. Z Kardiol 2002; 91: 147-55.

66. Berglin Blohm M, Hartford M, Karlsson T, Herlitz J: Factors associated with prehospital and inhospital delay time in acute myocardial infarction: a 6-year experience. J Intern Med 1998; 243: 243-50.

67. Yarzebski J, Goldberg RJ, Gore JM, Alpert JS: Temporal trends and factors associated with extent of delay to hospital arrival in patients with acute myocardial infarction: the Worcester Heart Attack Study. Am Heart J 1994; 128: 255-63.

68. Ottesen MM, Dixen U, Torp-Pedersen C, Kober L: Prehospital delay in acute coronary syndrome - an analysis of the components of delay. Int J Cardiol 2004; 96: 97-103.

69. Senges J, Schiele R: Prähospitalzeit - Patientenwissen allein reicht nicht aus. Z Kardiol 2004; 93 Suppl 1: 16-8.

70. Caldwell MA, Miaskowski C: Mass media interventions to reduce help-seeking delay in people with symptoms of acute myocardial infarction: time for a new approach? Patient Educ Couns 2002; 46: 1-9.e46.

71. Appels A, Kop WJ, Schouten E: The nature of the depressive symptomatology preceding myocardial infarction. Behav Med 2000; 26: 86-9.e47.

72. Ottolini F, Modena MG, Rigatelli M: Prodromal symptoms in myocardial infarction. Psychother Psychosom 2005; 74: 323-7. 